\title{
The Wnt5/Planar Cell Polarity Pathway Regulates Axonal Development of the Drosophila Mushroom Body Neuron
}

\author{
Kazumichi Shimizu, ${ }^{1,2}$ Makoto Sato, ${ }^{1,2}$ and Tetsuya Tabata ${ }^{1,2}$ \\ ${ }^{1}$ Institute of Molecular and Cellular Biosciences, University of Tokyo, Tokyo 113-0032, Japan, and ${ }^{2}$ Graduate Program in Biophysics and Biochemistry, \\ Graduate School of Science, University of Tokyo, Tokyo 113-0033, Japan
}

\begin{abstract}
Axonal development is a fundamental process for circuit formation in the nervous system and is dependent on many cellular events, including axon initiation, elongation, guidance, and branching. The molecular mechanisms underlying these events have been well studied, especially for axon guidance. In the presence of a guidance cue, the polarization of a growth cone precedes the turning response, which is one example of the diverse forms of cell polarity. Planar cell polarity (PCP) is another example of cell polarity. Although some PCP genes are required for axonal tract formation in vertebrates, it remains elusive whether these genes participate in a common PCP pathway concertedly. Here, we show that essential PCP signaling components, encoded by frizzled ( $f z)$, strabismus (stbm), flamingo ( fmi), and dishevelled $(d s h)$, are cooperatively required for axonal targeting and branching of the Drosophila mushroom body (MB) neurons. A detailed analysis of these mutants revealed that these components were required for the correct targeting and bifurcation of axons. In addition, we suggest that Wnt5 functions as a ligand in the PCP pathway in this process. Wnt 5 mutants showed similar phenotypes to PCP mutants at the single-cell level and genetically interacted with PCP genes. Wnt5 was broadly expressed in the developing brain. We propose that Wnt5 and the PCP pathway concertedly regulate axonal development of the MB.
\end{abstract}

\section{Introduction}

Brain function is based on the precise wiring of neural circuits. To construct such an accurate circuit, neurons must project their axons to correct targets during development. This process requires axon initiation, elongation, guidance, and branching. Growth cones are guided along specific pathways by attractive or repulsive guidance cues, such as Ephrin/Eph, semaphorins, netrins, and Robo/Slit (Chilton, 2006). In addition to these four families of guidance molecules, factors characterized in other developmental processes have been proven to guide the growth cones in recent years (Chilton, 2006). Components of the planar cell polarity (PCP) signaling pathway are examples of such factors (Wada and Okamoto, 2009; Tissir and Goffinet, 2010).

PCP refers to polarity within the plane of a cell sheet, and the molecular mechanisms underlying its generation have been stud-

Received Jan. 10, 2011; revised Feb. 2, 2011; accepted Feb. 7, 2011.

Author contributions: K.S., M.S., and T.T. designed research; K.S. performed research; K.S. and T.T. analyzed data; K.S. and T.T. wrote the paper.

This work was supported by Ministry of Education, Culture, Sports, Science, and Technology, Global Center of Excellence Program (Integrative Life Science Based on the Study of Biosignaling Mechanisms). A predoctoral fellowship provided support for K.S. from Japan Society for the Promotion of Science. We thank members of the Tabata Laboratory for helpful discussions. We also thank Y. Maeyama for her excellent technical help and Y. Nitta for unpublished data. We are grateful to P. N. Adler, J. D. Axelrod, S. Eaton, L. G. Fradkin, H. Hing, T. Lee, L. Luo, J. N. Noordermeer, R. Nusse, D. Strutt, J. B. Thomas, T. Uemura, T. Wolff, the Bloomington Stock Center, the National Institute of Genetics, the Drosophila Genetic Resource Center Kyoto, Vienna Drosophila RNAi Center, and Developmental Studies Hybridoma Bank for flies and antibodies.

The authors declare no competing financial interests.

M. Sato's present address: Frontier Science Organization, Kanazawa University 13-1, Takaramachi, Kanazawa, Ishikawa 920-8641, Japan.

Correspondence should be addressed to Tetsuya Tabata, Institute of Molecular and Cellular Biosciences, University of Tokyo, Yayoi 1-1-1, Bunkyo-ku, Tokyo 113-0032, Japan. E-mail: ttabata@iam.u-tokyo.ac.jp.

DOl:10.1523/JNEUROSCI.0154-11.2011

Copyright $\odot 2011$ the authors $\quad 0270-6474 / 11 / 314944-11 \$ 15.00 / 0$ ied in the epithelial polarization of Drosophila. Drosophila PCP genes include genes such as frizzled $(f z)$, strabismus ( $\mathrm{stbm})$, flamingo ( fmi), dishevelled (dsh), prickle ( $p k)$, and diego (dgo) (Simons and Mlodzik, 2008; Axelrod, 2009). The asymmetric distribution of these factors defines the planar axis within a cell. Vertebrate homologues of PCP genes are also important for both epithelial polarization and convergent extension (Simons and Mlodzik, 2008). PCP components in Drosophila and vertebrates are also involved in axon guidance, target recognition, and dendritic growth and maintenance (Takeichi, 2007; Wada and Okamoto, 2009). However, the relationship among PCP components in these processes has not been addressed, and it is also unclear whether these processes use the PCP signaling system per se.

In vertebrates, there is some evidence that Wnts function upstream of PCP components (Heisenberg et al., 2000; Kilian et al., 2003; Gros et al., 2009). However, relationships between Wnts and PCP components are still mostly unclear. Especially in Drosophila, no Wnt ligand acting upstream of PCP components has been identified.

In the present study, we demonstrate that PCP components function in the axonal development of the mushroom body (MB), the Drosophila third olfactory center. The MB is a paired neuropile structure composed of three types of Kenyon cells (KCs): $\gamma, \alpha^{\prime} / \beta^{\prime}$, and $\alpha / \beta$ (Lee et al., 1999). Each KC extends a primary neurite that bifurcates into a dendrite and an axon. The dendrites form a ball-like structure called the calyx (see Fig. $1 A, A^{\prime}, \mathrm{CA}$ ) near the cluster of cell bodies (see Fig. $1 A, A^{\prime}, \mathrm{CB}$ ), whereas the axons extend anteroventrally, forming a massive fiber tract called the peduncle (see Fig. $1 A, A^{\prime}$, PED). On the anterior side, the axons of $\gamma$ KCs turn medially and form the $\gamma$ lobe. However, axons of $\alpha^{\prime} / \beta^{\prime}$ and $\alpha / \beta$ KCs bifurcate to form four 
discrete lobes: the $\alpha^{\prime}, \beta^{\prime}, \alpha$, and $\beta$ lobes (see Fig. $1 A, A^{\prime}$ ). We found that $f z$, stbm, and $d s h$ functioned cooperatively in axon targeting and branching of KCs. In addition, we show genetic interactions between PCP components and Wnt5, suggesting that Wnt5 acts as a candidate ligand for PCP components in the regulation of the axonal development of the MB.

\section{Materials and Methods}

Fly strains. Wnt $5^{D 7}$ (Yoshikawa et al., 2003), Wnt $5^{400}$ (Fradkin et al., 2004), $f z^{H 51}$ (Jones et al., 1996), $f z^{D 21}, f z^{K 21}, s t b m^{A 3}$ (Taylor et al., 1998), $\mathrm{stbm}^{\text {stbm-6 }}$ (Wolff and Rubin, 1998), fmi ${ }^{E 59}$ (Usui et al., 1999), and $d g o^{380}$ (Feiguin et al., 2001) are null alleles or amorphic alleles. $d s h^{1}$ is a hypomorphic allele of $d s h . p k^{1}$ and $p k^{s p l e-1}$ are hypomorphic alleles that lack the expression of the sple and $p k$ isoforms, respectively. $p k^{p k-s p l e-13}$ is a null allele that lacks both the sple and the $p k$ isoforms (Gubb et al., 1999). The following Gal-4 lines were used to drive gene expression in KCs: OK107Gal4, NP7175-Gal4, c739-Gal4, and 7B-Gal4. The following transgenic strains were used in this study: UAS-GFP, UAS-mCD8::GFP (Lee et al., 1999), UAS-fz, UAS-stbm (Bastock et al., 2003), UAS-dsh (Rulifson et al., 1996), UAS-dsh $\triangle D E P$ (Axelrod, 2001), and UAS-Wnt5 (Fradkin et al., 2004). UAS-dsRNA lines ( $f z, 105493$; stbm, 7376; fmi, 107993; Wnt5, $101621)$ and UAS-dicer2 lines $(60008,60009)$ were obtained from the Vienna Drosophila RNAi Center stock center.

Clonal analysis. To generate single-cell clones in the MB, we used the mosaic analysis with a repressible cell marker (MARCM) technique (Lee and Luo, 1999). Pupae were heat-shocked at $37^{\circ} \mathrm{C}$ for $15 \mathrm{~min}$ for the FRT19A clones and for $5 \mathrm{~min}$ for the FRTG13 clones. The genotypes used were as follows: $y w / Y$; FRTG13 UAS-mCD8::GFP/ FRTG13 tubP-Gal80; hsFLP/+; OK107-Gal4/+, Wnt5 ${ }^{D 7} / Y$; FRTG13 UAS-mCD8::GFP/ FRTG13 tubP-Gal80; hsFLP/+; OK107-Gal4/+, dsh ${ }^{1} / Y$; FRTG13 UAS-mCD8::GFP/ FRTG13 tubP-Gal80; hsFLP/+; OK107-Gal4/+, FRT19A tubP-Gal80 hsFLP w/ $y w$ FRT19A; UAS-mCD8::GFP/+; OK107Gal4/+, FRT19A tubP-Gal80 hsFLP w/ yw FRT19A; UAS-mCD8::GFP I+; $f z^{H 51}$ ri FRT2A/fz ${ }^{D 21}$; OK107-Gal4/+, FRT19A tubP-Gal80 hsFLP w/ yw FRT19A; stbm ${ }^{\text {stbm-6 }} /$ stbm $^{A 3}$; UAS-mCD8::GFP /+; OK107-Gal4/+. To generate the Wnt5 mutant neuroblast clones in the MB, we used $W n t 5^{400}$. First- and second-instar larvae were heat-shocked five times for $1 \mathrm{~h}$ at $37^{\circ} \mathrm{C}$. The genotypes used were as follows: Wnt5 $5^{400}$ FRT19A/ FRT19A tubP-Gal80 hsFLP w; UAS-mCD8::GFP/+; OK107-Gal4/+.

Immunohistochemistry. Immunohistochemistry was performed as described previously (Huang and Kunes, 1996; Takei et al., 2004), except for the staining of the brains for Wnt5. The following primary antibodies were provided by the Developmental Studies Hybridoma Bank: mouse monoclonal anti-Fasciclin II (1D4 anti-Fasciclin II; 1:50), rat monoclonal anti-N-cadherin (DN-EX no. 8; 1:10), and mouse monoclonal antiFlamingo (Flamingo no. 74; 1:10). Rabbit anti-Fz (Bastock and Strutt, 2007) and rabbit anti-Stbm (Rawls and Wolff, 2003) were used at dilutions of 1:300, and 1:500, respectively. Rabbit anti-green fluorescent protein (GFP) Alexa Fluor 488 conjugate was used at a dilution of 1:2000 (Invitrogen). The following secondary antibodies were used at a dilution of 1:200: anti-mouse Cy3 (Jackson ImmunoResearch), anti-mouse FITC (Jackson ImmunoResearch), anti-rat Cy3 (Jackson ImmunoResearch), and anti-rabbit Alexa Fluor 660 (Invitrogen). Specimens were mounted with Vectashield mounting medium (Vector Laboratories) and viewed on a Zeiss LSM 710, a Zeiss LSM 510, a Zeiss LSM 5 EXCITER, or an Olympus FV1000 confocal microscope.

Generation of the Wnt5 antibody. A rabbit anti-Wnt5 antibody was raised against a previously described region and affinity purified (Fradkin et al., 1995), except that a His-tagged immunogen was used instead of a trpE fusion protein (Takara Bio).

Wnt5 staining of larval and pupal brains. Wnt 5 staining was performed as previously described with slight modifications (Yao et al., 2007). Dissected brains were incubated with anti-Wnt5 (1:500) in PBS overnight at $4^{\circ} \mathrm{C}$, washed twice for $5 \mathrm{~min}$ at room temperature, and fixed with PLP (paraformaldehyde/lysine/periodate) fixative for $1 \mathrm{~h}$ at room temperature.

Classification of mutant phenotypes. To classify the mutant phenotypes, we measured the width of the $\alpha$ and the $\beta$ lobes at the middle of their lengths in a three-dimensional image reconstructed by Imaris software
(Bitplane). We classified the MB as "normal" if the width of both the $\alpha$ lobe and the $\beta$ lobe was above the cutoff values. If the width of either the $\alpha$ lobe or the $\beta$ lobe was below the cutoff value, the phenotype of the MB was classified as "lobe reduction." When either or both of the $\alpha$ and $\beta$ lobes were completely absent, we classified the MB as "lobe loss." The MBs in which all of the $\alpha / \beta$ neurons aggregated beside the calyx were classified as "posterior aggregation." The cutoff values were set by subtracting $3 \times$ SD from the mean width of wild type (mean, 23.91 pixels, and SD, 1.99 pixels, for the $\alpha$ lobes of the Canton S females; mean, 22.70 pixels, and SD, 2.50 pixels, for the $\beta$ lobes of the Canton $S$ females; mean, 25.93 pixels, and SD, 2.19 pixels, for the $\alpha$ lobes of the Canton $S$ males; and mean, 23.72 pixels, and SD, 2.63 pixels, for the $\beta$ lobes of the Canton $S$ males).

Comparison of the signals of Wnt5 and N-cadherin in the Wnt5 mutant clone. To eliminate the noise outside of the calyx, background signals were subtracted from the images of the single channels for both Wnt5 and N-cadherin using ImageJ software (National Institutes of Health, Bethesda, MD). The subtracted image for Wnt 5 was divided by that for $\mathrm{N}$-cadherin and visualized by the height of the peaks in 2.5-dimensional images. We could obtain a similar result without subtraction of the background signals.

\section{Results}

Drosophila PCP components are expressed in the MB

To analyze the function of the PCP signal in neural development, we searched for neural tissues expressing Fz, one of the core PCP signaling components. Fz was expressed strongly in the core and weakly in the periphery along the entire tract of the lobes and the peduncle of the MB throughout its development (Fig. $1 E-G^{\prime}$ ). Because the younger axons of KCs run within the core of the $\mathrm{MB}$, $\mathrm{Fz}$ was expected to be expressed strongly in the axons of younger KCs and weakly in the axons of older KCs.

We also examined the expression patterns of other PCP components and found that Stbm, Fmi were specifically expressed in the core of the $\mathrm{MB}$ (Fig. $1 H-J^{\prime}$ ) (data not shown). The expression of these components in the MB was abolished in the corresponding mutants, confirming the specificity of the antibodies (data not shown). Therefore, the major PCP signaling components examined were all expressed in the axons of younger KCs. These observations suggest the possible involvement of the PCP signal in axonal development of the MB.

\section{$f z, s t b m$, and $d s h$ are required for the correct targeting and branching of $\mathrm{MB}$ axons}

To address whether the PCP signal has a role in the axonal development of the MB, we examined the structure of the MB in $f z$, stbm, and $d s h$ mutants (Fig. 2). We used transheterozygotes of the null alleles for $f z\left(f z^{H 51}\right.$ and $\left.f z^{D 21}\right)$ or $s t b m\left(s t b m^{s t b m-6}\right.$ and $\left.s t b m^{A 3}\right)$ and homozygotes or hemizygotes of a hypomorphic allele for $d s h$ $\left(d s h^{1}\right) . d s h^{1}$ is an allele that mainly affects the PCP pathway, but not the Armadillo-dependent Wnt pathway (Axelrod et al., 1998; Boutros et al., 1998). The five distinct lobes were visualized by double labeling with an anti-Fasciclin II (FasII) antibody (Crittenden et al., 1998) and with GFP expression driven by OK107Gal4 (Connolly et al., 1996). The anti-FasII antibody stained the $\alpha / \beta$ lobes strongly and the $\gamma$ lobe weakly (Fig. $2 A, A^{\prime}$ ). The most apparent phenotype was a reduction or absence of the $\alpha$ or $\beta$ lobes. The $\alpha$ lobes were lost or reduced in $50.7,0.926$, and $27.4 \%$, and the $\beta$ lobes were lost or reduced in $16.9,38.0$, and $8.33 \%$ of adult hemispheres for the $f z^{H 51} / \mathrm{fz}^{D 21}, \mathrm{stbm} \mathrm{stbm-6}^{\mathrm{stb}} \mathrm{st} \mathrm{m}^{\mathrm{A3}}$, and $d s h^{1}$ mutants, respectively (Fig. $2 B-D^{\prime}$, arrowheads). The $\alpha^{\prime}$ lobes were also lost or reduced, although the penetrance was relatively low $\left(16.9 \%\right.$ for $f z^{H 51} / f z^{D 21}, 0.00 \%$ for $s t b m^{s t b m-6} / s t b m^{A 3}$, and $23.8 \%$ for $d s h^{1}$ ), and the $\beta^{\prime}$ lobes appeared not to be affected. In the more severe cases in the $d s h^{1}$ mutants, $\mathrm{KC}$ axons failed to 
A
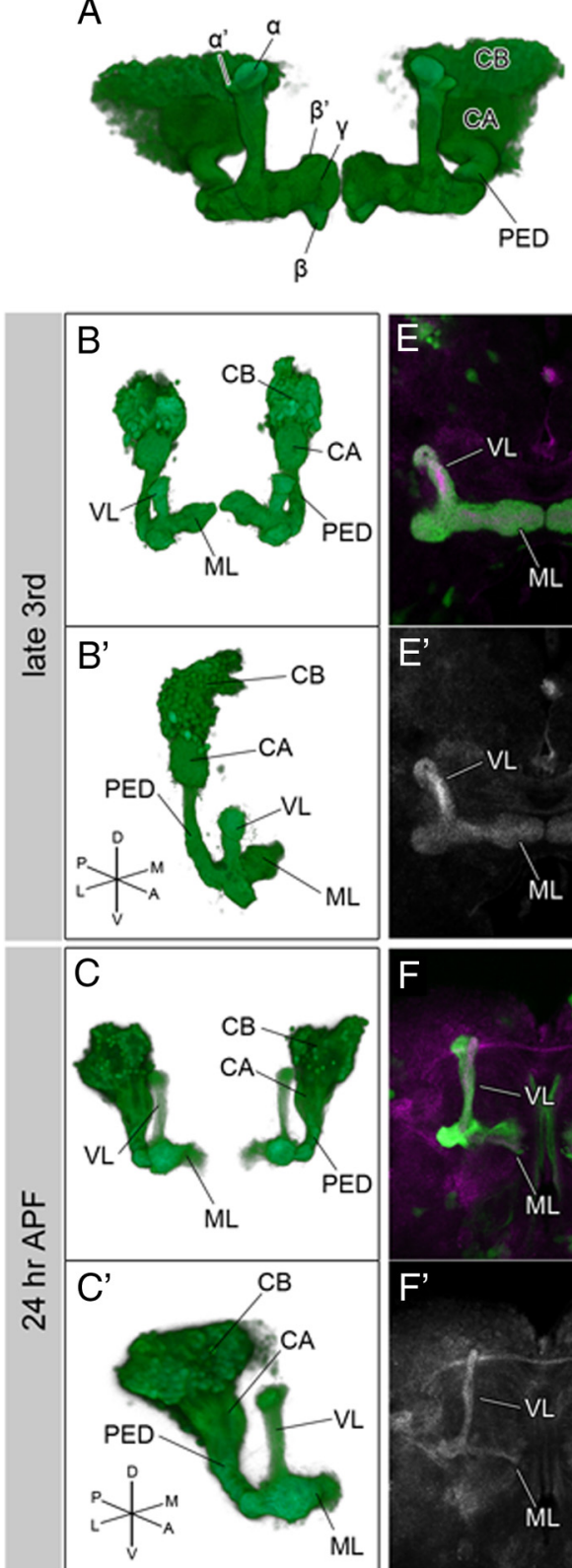

$\mathrm{ML}$

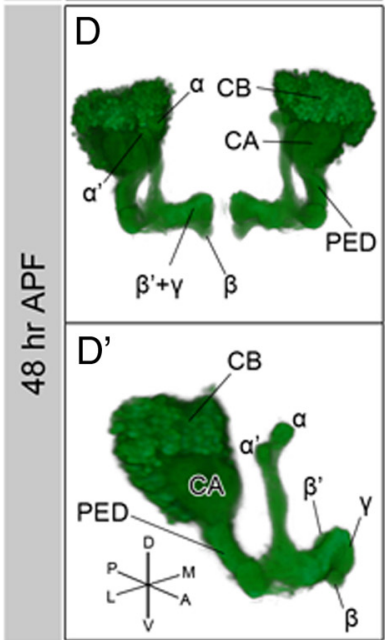

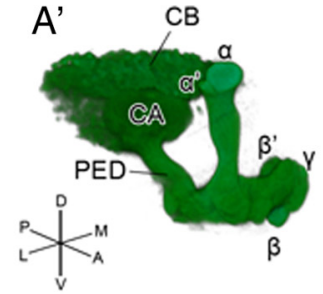
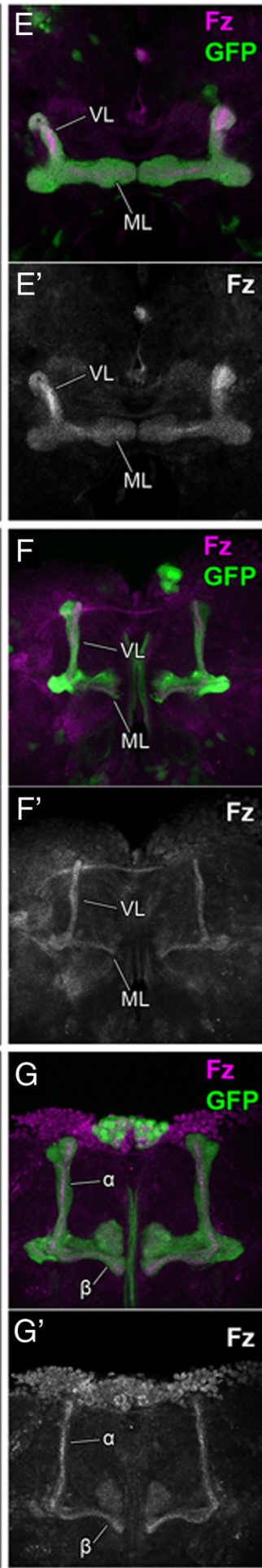
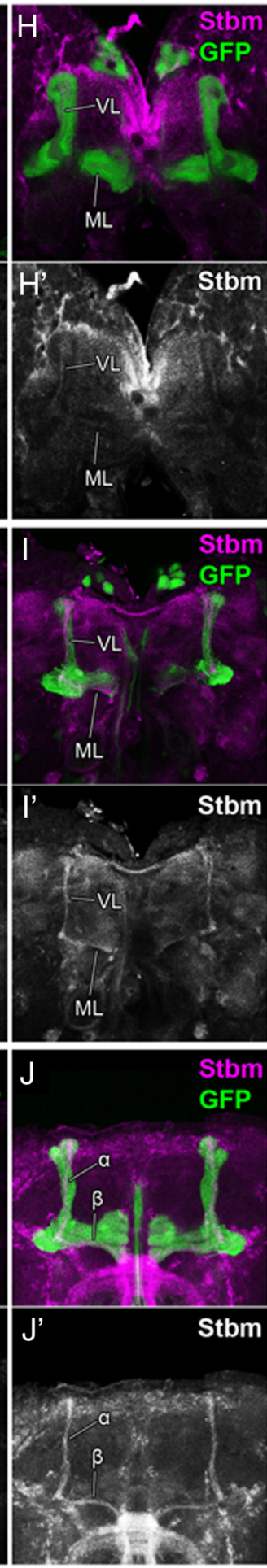

Figure 1. The expression patterns of the $P C P$ components during the development of the MB. $A-D$, Structure of the $M B$ in the adult $\left(\boldsymbol{A}, \boldsymbol{A}^{\prime}\right)$, at the late third larval instar $\left(\boldsymbol{B}, \boldsymbol{B}^{\prime}\right), 24 \mathrm{~h} \operatorname{APF}\left(\boldsymbol{C}, \boldsymbol{C}^{\prime}\right)$, and $48 \mathrm{~h} \operatorname{APF}\left(\boldsymbol{D}, \boldsymbol{D}^{\prime}\right)$. Anterior perspectives of whole MBs $(\boldsymbol{A}-\boldsymbol{D})$ and oblique perspectives of right $\mathrm{MBs}\left(\boldsymbol{A}^{\prime}-\boldsymbol{D}^{\prime}\right)$ are indicated. $\boldsymbol{E}-\boldsymbol{J}^{\prime}$, Expression patterns of $\mathrm{Fz}\left(\boldsymbol{E}-\boldsymbol{G}\right.$, magenta; $\boldsymbol{E}^{\prime}-\boldsymbol{G}^{\prime}$, white $)$ and

project anteriorly and formed a ball-like aggregate beside the calyx and cell body $(1.19 \%)$ (Fig. 2E, $E^{\prime}, G, G^{\prime}$, arrow). Because an absence of the $\alpha^{\prime}$ lobes was always associated with a loss of the $\alpha$ lobes ( $n=23$ for $f z^{H 51} / f z^{D 21}$ and $n=19$ for $\left.d s h^{1}\right)$, for the following analyses, the mutant phenotypes were scored by examining the structure of the anti-FasII-stained $\alpha / \beta$ lobes as a measure. We assumed that the phenotype of an absence of the $\alpha$ lobes involved the loss of the $\alpha^{\prime}$ lobes. Because a null allele of $f m i\left(f m i^{E 59}\right)$ is a lethal allele, fmi was instead knocked down in the MB using RNA interference (RNAi) with OK107-Gal4; UAS-fmi dsRNA, and defects similar to the $f z^{H 51} / f z^{D 21}, s t b m^{s t b m-6} /$ $s t b m^{A 3}$, and $d s h^{1}$ mutants were observed (data not shown). Mutants of another core PCP gene, $p k$, showed the above phenotypes with a relatively low penetrance $\left(2.78 \%, n=36\right.$ for $p k^{1} ; 17.6 \%, n=34$ for $p k^{\text {sple-1 }} ; 23.8 \%, n=42$ for $p k^{p k-s p l e-13}$ ) (data not shown). dgo mutants showed no phenotype (data not shown).

Because individual $\alpha / \beta$ and $\alpha^{\prime} / \beta^{\prime}$ neurons bifurcate dorsally and medially to form the $\alpha / \beta$ and $\alpha^{\prime} / \beta^{\prime}$ lobes, the phenotypes of the $\alpha, \beta$, and $\alpha^{\prime}$ neurons described above can be explained by defects in branch formation or the mistargeting of the bifurcated sister branches toward the same direction. To distinguish between these two possibilities, we used the MARCM technique in which clones of cells are generated by mitotic recombination and marked by the expression of mCD8::GFP (Lee and Luo, 1999). We induced a MARCM clone in the wild type or mutant background using FRT19A for $f z^{H 51} / f z^{D 21}$ and $s t b m^{s t b m-6} / s t b m^{A 3}$ or FRTG13 for $d s h^{1}$ (Fig. $2 H-\mathrm{O}^{\prime \prime \prime}$ ). In the wild type, an individual $\alpha / \beta$ neuron extended a single axon within the peduncle and bifurcated at the anterior end of the peduncle to form the vertical and medial branches (Fig. $2 H, H^{\prime}, M, M^{\prime}$ ). An overbranching at the branch point of the lobes was occasionally observed $(12.0 \%, n=25$

\section{$\leftarrow$}

Stbm ( $\boldsymbol{H}-\boldsymbol{J}$, magenta; $\boldsymbol{H}^{\prime}-\boldsymbol{J}^{\prime}$, white) at the third larval instar $\left(\boldsymbol{E}, \boldsymbol{E}^{\prime}, \boldsymbol{H}, \boldsymbol{H}^{\prime}\right), 24 \mathrm{~h} \mathrm{APF}\left(\boldsymbol{F}, \boldsymbol{F}^{\prime}, \boldsymbol{I}, \boldsymbol{I}^{\prime}\right)$, and $48 \mathrm{~h} \mathrm{APF}\left(\boldsymbol{G}, \boldsymbol{G}^{\prime}, \boldsymbol{J}, \boldsymbol{J}^{\prime}\right)$. All of the PCP components examined were expressed in the core of the MB during the entire period of $M B$ development. The structures of the MBs were visualized by the expression of GFP (green) driven by OK107-Gal4. The abbreviations are as follows: CB, Cell bodies; $C X$, calyx; PED, peduncle; VL, vertical lobe; ML, medial lobe. Because the lobes at the late third larval instar and $24 \mathrm{~h}$ APF do not have clearly discrete lobes that are composed of distinct subtypes of KCs, the lobes are simply indicated as the vertical lobes (VL) and the medial lobes (ML) in $B-C^{\prime}, E-F^{\prime}$, and $\boldsymbol{H}-\boldsymbol{I}^{\prime}$. 

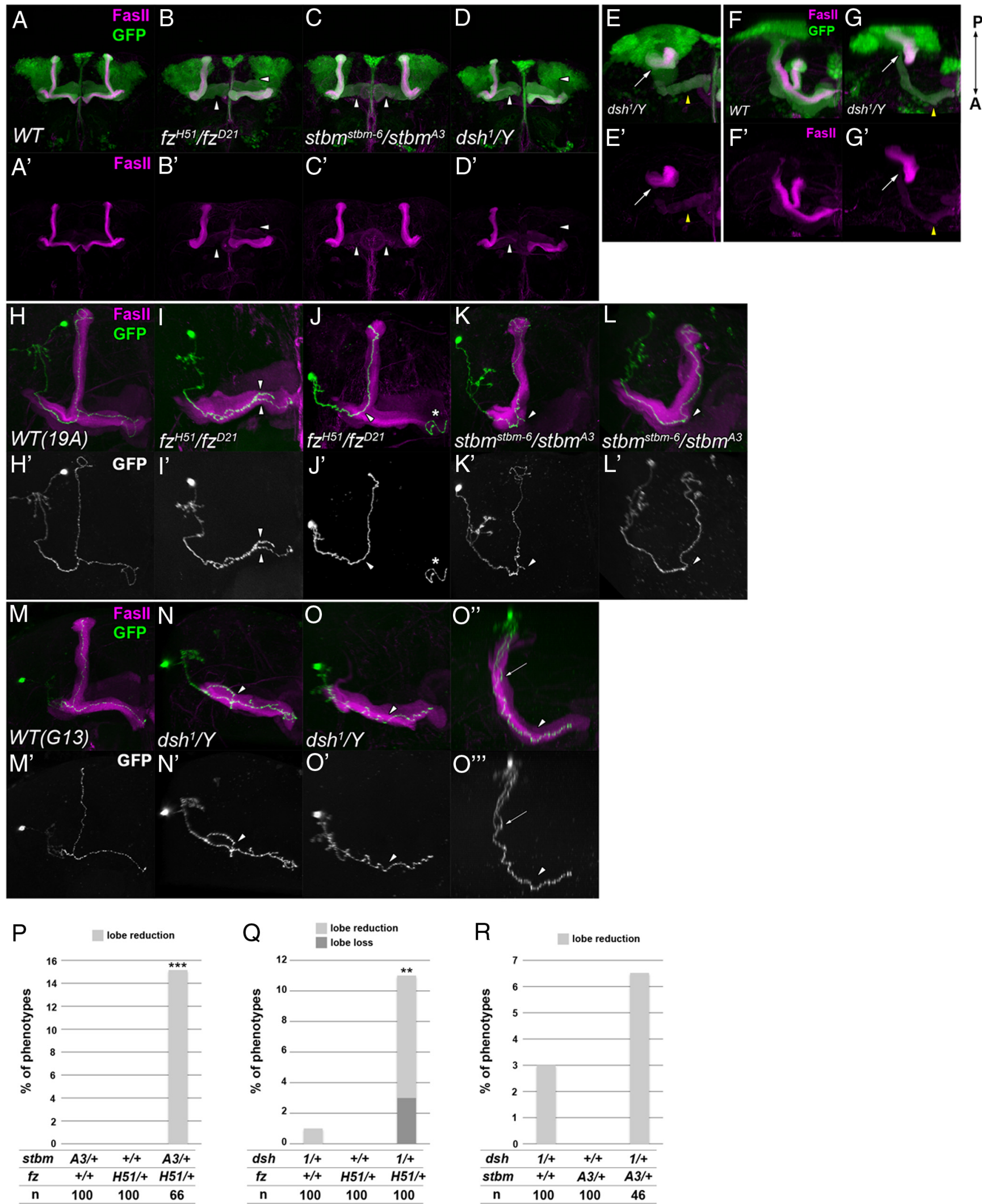

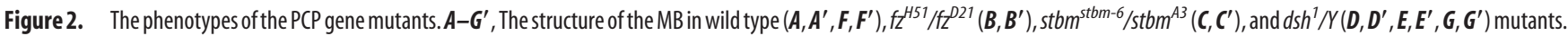
The vertical or medial lobes were lost or reduced in the PCP mutants $\left(\boldsymbol{B}-\boldsymbol{D}^{\prime}\right.$, arrowheads). Anterior $\left(\boldsymbol{A}-\boldsymbol{E}^{\prime}\right)$ and dorsal views with the posterior side up and the anterior side down $\left(\boldsymbol{F}-\boldsymbol{G}^{\prime}\right)$ are indicated. In $d s h^{7}$ mutants, a loss or reduction of the lobes $\left(\boldsymbol{D}, \boldsymbol{D}^{\prime}\right.$, arrowheads) or an aggregation of axons beside the calyx $\left(\boldsymbol{E}, \boldsymbol{E}^{\prime}, \boldsymbol{G}, \boldsymbol{G}^{\prime}\right.$, arrow) was observed. In the case of axon aggregation, only a small portion of the $\gamma$ neurons projected toward the anterior side $\left(\boldsymbol{E}, \boldsymbol{E}^{\prime}, \mathbf{G}, \boldsymbol{G}^{\prime}\right.$, yellow arrowhead). The MB was visualized by the expression of GFP driven by $0 K 107-G a l 4$ (green) and the $\gamma$ and $\alpha / \beta$ lobes were visualized by anti-Fasll antibody (magenta). $\boldsymbol{H}-\mathbf{O}^{\prime \prime \prime}$, The axonal projections of $\alpha / \beta \mathrm{KC}$ s marked by GFP $\left(\boldsymbol{H}-\mathbf{O}, \boldsymbol{O}^{\prime \prime}\right.$, green; $\boldsymbol{H}^{\prime}-\mathbf{O}^{\prime}, \mathbf{O}^{\prime \prime}$, white) in wild type (FRT $19 A$ control clone in $\boldsymbol{H}, \boldsymbol{H}^{\prime} ; F R T$ G13

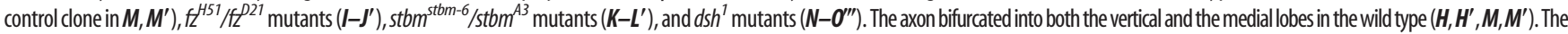
projection of sister branches in the same direction $\left(\boldsymbol{I}, \boldsymbol{I}^{\prime}\right.$, arrowheads), the stalling of the branched axon $\left(\boldsymbol{K}, \boldsymbol{K}^{\prime}\right.$, arrowhead), and the reversed projection of the branched axon into (Figure legend continues.) 
for the FRT19A control clone; 3.23\%, $n=$ 31 for the FRTG13 control clone). However, in the $f z^{H 51} / f^{D 21}, s t b m^{s t b m-6} / s t b m^{A 3}$, and $d s h^{1}$ mutants, guidance defects encompassing the projection of sister branches toward the same direction and the stalling of the bifurcated branch along the lobe or the peduncle were observed (guidance defects) (Fig. 2I, $I^{\prime}, 37.2 \%, n=$ 43 for $f z^{H 51} / f z^{D 21} ; K, K^{\prime}, 20.5 \%, n=39$ for $\mathrm{stbm}^{\text {stbm-6}} / \mathrm{stbm}^{A 3} ; \mathrm{N}, \mathrm{N}^{\prime}, 15.5 \%, n=58$ for $\left.d s h^{1}\right)$. We also noticed defects in branch formation, including an ectopic branch at the peduncle, an overbranching at the branch point of the lobes and no branch at the branch point of the lobes (branching defects) (Fig. 2J,J', 25.6\%, $n=43$ for $f z^{H 51} / f z^{D 21} ; L, L^{\prime}, 43.6 \%, n=39$ for $s t b m^{\text {stbm-6 }} / \mathrm{stbm}^{A 3}$; O-O $\mathrm{O}^{\prime \prime \prime}, 32.8 \%, n=$ 58 for $\left.d s h^{l}\right)$. All of the clones extended axons beyond the branch point of the lobes regardless of the branching phenotype. These results suggest that $f z$, stbm, and $d s h$ are required for the correct branching and targeting of the axons of KCs, but not for the extension of axons.

Next, we examined genetic interactions among PCP genes to address whether these genes function in a cooperative manner. To assess the mutant phenotypes, we measured the width of $\alpha$ and $\beta$ lobes in three-dimensional reconstructed images and classified the MBs into four classes: posterior aggregation, lobe loss, lobe reduction, and normal. Double heterozygotes of any two of $\mathrm{fz}^{\mathrm{H} 51}$, $s t b m^{A 3}$, and $d s h^{1}$ showed loss or reduction of the $\alpha / \beta$ lobes (Fig. $2 P$, stbm $\mathrm{A}^{3} /+; f z^{\mathrm{H} 51} /+$, value of $p$ is $6.4 \times$ $10^{-5} ; Q, d s h^{1} /+; f z^{H 51} /+$, value of $p$ is 0.0067 using Fisher's exact test) with the phenotype of $d s h^{1} /+$; stbm $m^{A 3} /+$ being much less prominent (Fig. $2 R$, value of $p$ is 0.38 ), although single heterozygotes of these genes showed no or little defects in the MB. These results suggest that the PCP genes cooperatively function in the axonal development of the MB.

\section{$f z$, stbm, and $d s h$ function in the KCs during axonal development of the MB}

Based on their expression patterns, the PCP components were expected to function in the KCs during axonal development of the MB. To confirm this, we attempted to rescue mutants of the PCP components using c739-Gal4, NP7175-Gal4, or 7B-Gal4, all of which are expressed in the developing MB. The lobe loss, lobe reduction, or posterior aggregation of the $\alpha / \beta$ lobes in $z^{H 51} / f z^{D 21}$

(Figure legend continued.) the peduncle $\left(\boldsymbol{N}, \boldsymbol{N}^{\prime}\right.$, arrowhead) are shown as examples of guidance defects. The absence of branches $\left(\boldsymbol{J}, \boldsymbol{J}^{\prime}, \mathbf{L}, \boldsymbol{L}^{\prime}, \mathbf{O}-\mathbf{O}^{\prime \prime \prime}\right.$, arrowhead) is shown as an example of branching defects. In $\mathbf{0}-\mathbf{O}^{\prime \prime \prime}$, an ectopic branch at the peduncle projected in the posterior direction (arrow). $\boldsymbol{O}^{\prime \prime}$ and $\mathbf{O}^{\prime \prime}$ are the dorsal views of $\mathbf{O}$ and $\boldsymbol{O}^{\prime}$, respectively. The asterisks in $\boldsymbol{J}$ and $\boldsymbol{J}^{\prime}$ indicate an axon of a clone induced in the contralateral MB. $\boldsymbol{P}-\boldsymbol{R}$, Genetic interaction between the PCP genes. Double heterozygotes of the $s t b m^{A 3}$ and $f_{z}^{H 51}(\boldsymbol{P}), d s h^{7}$ and $f z^{H 51}(\boldsymbol{Q})$, or $d s h^{7}$ and $s t b m^{A 3}(\boldsymbol{R})$ showed a higher percentage of defects in the MB than single heterozygotes of $f^{H}{ }^{H 51}$, $s t b m^{A 3}$, and $d s h^{1}\left({ }^{* * *} p<0.001,{ }^{* *} p<0.01\right.$, Fisher's exact test).

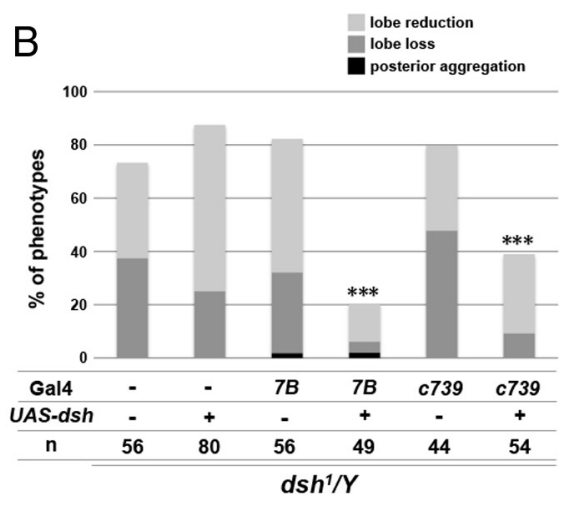

F
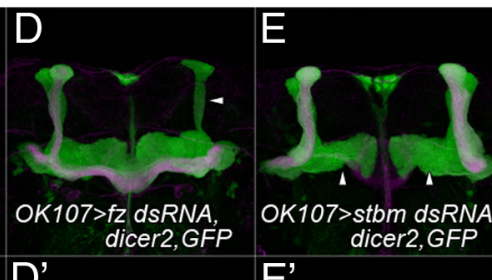

OK107>stbm dsRNA

Stbm dSRNA, OK107>

dicer2, GFP dsh $\triangle D E P, G F P$
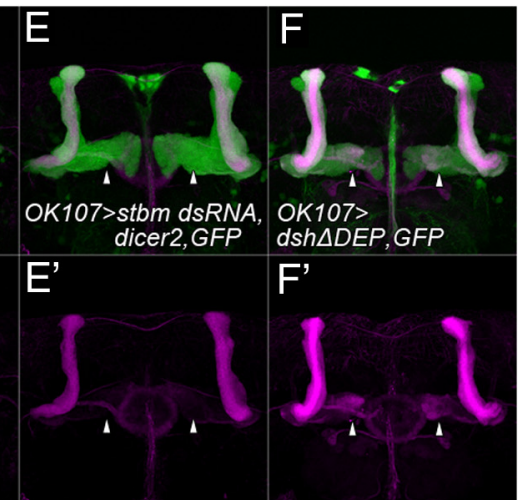

Figure 3. The PCP genes function in the developing MB. $\boldsymbol{A}, \boldsymbol{B}$, Quantification of MB defects in $f_{z} \mathrm{H}^{451} / \mathrm{fz}^{\mathrm{D21}}(\boldsymbol{A})$ and $d s h^{7}$ mutants $(\boldsymbol{B})$ with the indicated transgenes. Specific expression of exogenous $f z$ or $d s h$ in the MB by c739-Gal4 or NP7175Dsh (dsh $\triangle D E P)\left(\boldsymbol{F}_{\boldsymbol{F}} \boldsymbol{F}^{\prime}\right)$ was used. The cells expressing $f z$ ds RNA, stbm dsRNA, or dsh $\triangle D E P$ were marked by the expression (green) under the control of OK107-Gal4, and the $\gamma$ and $\alpha / \beta$ lobes were visualized by anti-Fasll (magenta). fz RNAi, stbm RNAi, and the expression of $d s h \triangle D E P$ resulted in the loss or reduction of the lobes (arrowheads) in $28.3 \%(n=60)$, $42.3 \%(n=52)$, and $22.5 \%(n=40)$ of cases, respectively.

mutant males was rescued by the expression of exogenous $f z$ by c739-Gal4 or NP7175-Gal4 (Fig. 3A). Similarly, MB-specific expression of the wild-type $d s h$ by $7 B$-Gal4 or $c 739-G a l 4$ rescued the $d s h^{1}$ mutant phenotype (Fig. $3 B$ ). The rescue experiment was not conducted for $s t b m$ because UAS-stbm rescued the $s t b m^{s t b m-6}$ / $s t b m^{A 3}$ mutant phenotype by itself, without Gal4 drivers. These results suggest that the PCP genes, at least $f z$ and $d s h$, function in the KCs in axonal development of the MB. Consistent with these results, the MB-specific knockdown of $f z$ and $s t b m$ by RNAi or the overexpression of the dominant-negative form of $d s h(d s h \triangle D E P)$ using OK107-Gal4 resulted in phenotypes similar to those of the corresponding mutants (Fig. $3 D-F^{\prime}$ ). The above results and the protein localization patterns suggest that the PCP components function in the MB during its development.

\section{Wnt5 is a candidate ligand for the PCP components during} the axonal development of the $\mathrm{MB}$

A Wnt ligand for $\mathrm{Fz}$ or Stbm had not yet been discovered in the Drosophila PCP pathway (Simons and Mlodzik, 2008; Axelrod, 2009). We searched for ligands of the PCP components that could participate in the axonal development of the MB. Wnt5, which functions as a repulsive guidance cue for Derailed (Drl) in the embryonic CNS (Yoshikawa et al., 2003), has been previously shown to be required for the development of the MB (Grillenzoni et al., 2007). As reported by Grillenzoni et al. (2007), we also observed that $W n t 5^{D 7}$ mutants showed a loss of the $\alpha / \beta$ lobes in 

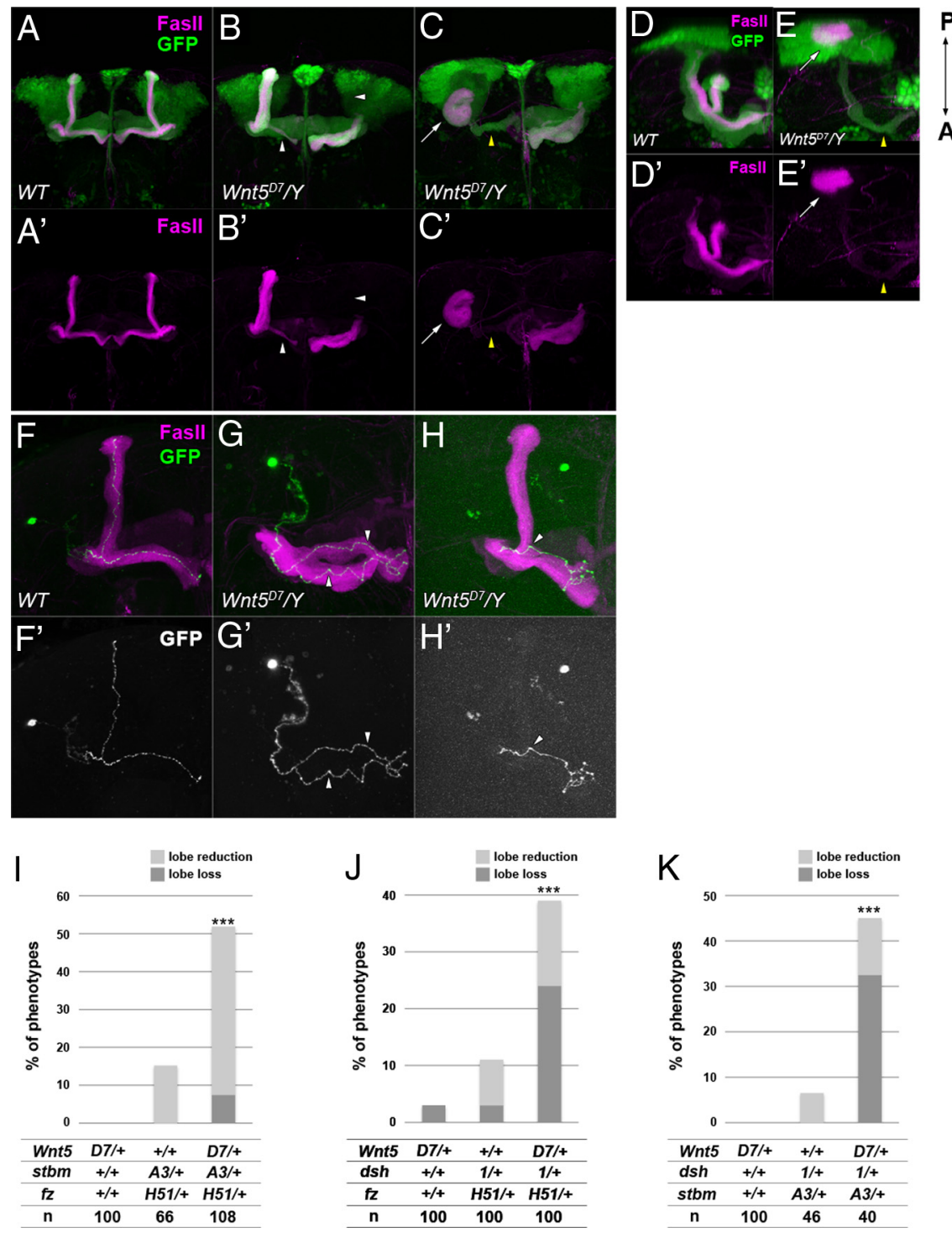

Figure 4. The mutant phenotype of $W n t 5^{D 7}$ and the genetic interaction between $W n t 5^{D 7}$ and mutants of the PCP genes. $A-E^{\prime}$ The structure of the $M B$ of wild type $\left(\boldsymbol{A}, \boldsymbol{A}^{\prime}, \boldsymbol{D}, \boldsymbol{D}^{\prime}\right)$ and $W n t 5^{D 7}$ mutants $\left(\boldsymbol{B}, \boldsymbol{B}^{\prime}, \boldsymbol{C}, \boldsymbol{C}^{\prime}, \boldsymbol{E}, \boldsymbol{E}^{\prime}\right)$. The MB was visualized by the expression of GFP driven by OK107-Gal4 (green), and the $\gamma$ and $\alpha / \beta$ lobes were visualized by an anti-Fasll antibody (magenta). Anterior $\left(\boldsymbol{A}-\boldsymbol{C}^{\prime}\right)$ and dorsal views with the posterior side up and the anterior side down $\left(\boldsymbol{D}-\boldsymbol{E}^{\prime}\right)$ are indicated. In $W n t 5^{D 7}$ mutants, a loss or reduction of the lobes $\left(\boldsymbol{B}, \boldsymbol{B}^{\prime}\right.$, arrowheads) or an aggregation of axons beside the calyx $\left(\boldsymbol{C}, \boldsymbol{C}^{\prime}, \boldsymbol{E}, \boldsymbol{E}^{\prime}\right.$, arrows) was observed. In the case of axon aggregation, only a small portion of the $\gamma$ neurons projected toward the anterior side ( $\boldsymbol{C}, \boldsymbol{C}^{\prime}, \boldsymbol{E}, \boldsymbol{E}^{\prime}$, yellow arrowheads). $\boldsymbol{F}-\boldsymbol{H}^{\prime}$, The axonal projection of $\alpha / \beta \mathrm{KC}$ s marked by GFP $\left(\boldsymbol{F}-\boldsymbol{H}\right.$, green; $\boldsymbol{F}^{\prime}-\boldsymbol{H}^{\prime}$, white) in wild type $\left(\boldsymbol{F}, \boldsymbol{F}^{\prime}\right)$ and $W n t 5^{D 7}$ mutants $\left(\mathbf{G}-\boldsymbol{H}^{\prime}\right)$. The axon bifurcated into both the vertical and the medial lobes in the wild type $\left(\boldsymbol{F}, \boldsymbol{F}^{\prime}\right)$. Projection of sister branches in the same direction $\left(\boldsymbol{G}, \boldsymbol{G}^{\prime}\right.$, arrowheads) and the absence of the branch $\left(\boldsymbol{H}, \boldsymbol{H}^{\prime}\right.$, arrowhead) are shown as examples of guidance defects and branching defects, respectively. $\boldsymbol{I}-\boldsymbol{K}$, Genetic interaction between $W n t 5$ and the PCP genes. The percentage of the observed phenotypes increased in the triple heterozygotes of $W n t 5^{D 7}, s t b m^{A 3}$, and $f z^{H 51}(I), W n t 5^{D 7}, d s h^{7}$, and $f_{z}{ }^{H 51}(J)$, and $W n t 5^{D 7}, d s h^{7}$, and $s t b m^{A 3}(\boldsymbol{K})$, but single heterozygotes of $W n t 5^{D 7}$ or double heterozygotes of any two of $f^{H 51}{ }^{H s t b m^{A 3}}$, and dsh ${ }^{7}$ showed little or no defect in the $M B\left({ }^{* * *} p<0.001\right.$, Fisher's exact test).

$50.0 \%$ of the cases when the OK107-Gal4 and UAS-GFP transgenes were combined to label the whole $\mathrm{MB}$ (Fig. $4 B, B^{\prime}$, arrowheads) $(n=68)$. In the more severe cases, posterior aggregation of axons was observed $(16.2 \% ; n=68)$ (Fig. $4 C, C^{\prime}, E, E^{\prime}$, arrow). $W n t 5^{D 7}$ mutants without either of the OK107-Gal4 or the UASGFP transgenes showed a lower penetrance (see Fig. $6 \mathrm{~A}$ ), perhaps because of the different genetic backgrounds of these two genotypes.

The following phenotypes were observed in single-cell clones induced in $W n t 5^{D 7}$ mutants using FRTG13: the projection of sister branches in the same direction and the stalling of bifurcated axons (guidance defects) (Fig. 4G, $G^{\prime}, 16.9 \%, n=71$ ) and ectopic branch formation and the loss of the branch at the branch point of the lobes (branching defects) (Fig. $4 H, H^{\prime}, 18.3 \%$, $n=71$ ). These results suggest that Wnt5 is not required for the extension of $\mathrm{KC}$ axons but is required for branch formation and the correct targeting of sister branches.

From the similarity of the phenotypes at the single-cell level (Figs. 2, 4) and the well known function of Wnts as ligands for Fzs in the canonical Wnt pathway, we inferred that Wnt5 functions as a candidate ligand for the PCP pathway in the axonal development of the MB. To verify this possibility, we examined the genetic interaction between Wnt5 and two PCP genes (Fig. 4I-K). Single heterozygotes of $W n t 5^{D 7}$ or double heterozygotes of any two of $f z^{H 51}, s t b m^{A 3}$, and $d s h^{1}$ showed no or little defect in the structure of the MB. However, in a significant proportion of triple heterozygotes of the $W n t 5^{D 7}$ and mutants of two PCP genes (Fig. 4I, $W n t 5^{D 7} /+; s t b m^{A 3} /+; f z^{H 51} /+; J, W n t 5^{D 7} /$ $d s h^{1} ; f^{H 51} /+$; or $\left.K, W n t 5^{D 7} / d s h^{1} ; s t b m^{A 3} /+\right)$, defects in the lobe structure were found. These results suggest that Wnt5 and the PCP genes function in the same or parallel pathways and raise the possibility that Wnt5 functions as a ligand for the PCP components.

\section{Wnt5 is broadly expressed in the developing brain}

We next examined the Wnt5 expression pattern using an anti-Wnt5 antibody (Fig. 5). Wnt5 was detected in almost all neuropile regions, except the peduncle and the lobes of the $\mathrm{MB}$, at the late third larval instar (Fig. 5B- $E^{\prime}$ ) and the $24 \mathrm{~h}$ (Fig. $5 \mathrm{H}-$ $\left.J^{\prime}\right)$ and $48 \mathrm{~h}$ after puparium formation (APF) (Fig. 5M-O'). These expression patterns were completely abolished in the Wnt5 mutant brains (Fig. 5A, $A^{\prime}, G, G^{\prime}, L, L^{\prime}$ ). Within the MB, Wnt5 was detected in the calyx at all stages (Fig. $5 B, B^{\prime}, H, H^{\prime}, M, M^{\prime}$, dotted circle). Wnt5 was also localized at the branch point of the lobes (Fig. $5 J, J^{\prime}, O, O^{\prime}$, arrow) and the tips of the medial lobes at 24 and $48 \mathrm{~h} \mathrm{APF}$ (Fig. $5 \mathrm{~J}, \mathrm{~J}^{\prime}, \mathrm{O}, \mathrm{O}^{\prime}, \mathrm{ML}$ ) and the tips of the vertical lobes at $48 \mathrm{~h}$ APF (Fig. 5O, $O^{\prime}, \mathrm{VL}$ ). Because the KCs begin to extend their axons along the edge of the calyx at the initial phase of axon projection and then extend these axons within the core of the peduncle and lobes, their growth cones pass through two points, the calyx and the branch point of the lobes, where they could easily contact the accumulated Wnt5.

Next, we addressed whether the expression of Wnt5 in the calyx had a role in the axonal development of the MB using several rescue experiments to restore the expression of Wnt5 in the calyx. We used the same phenotype categorization as was used 


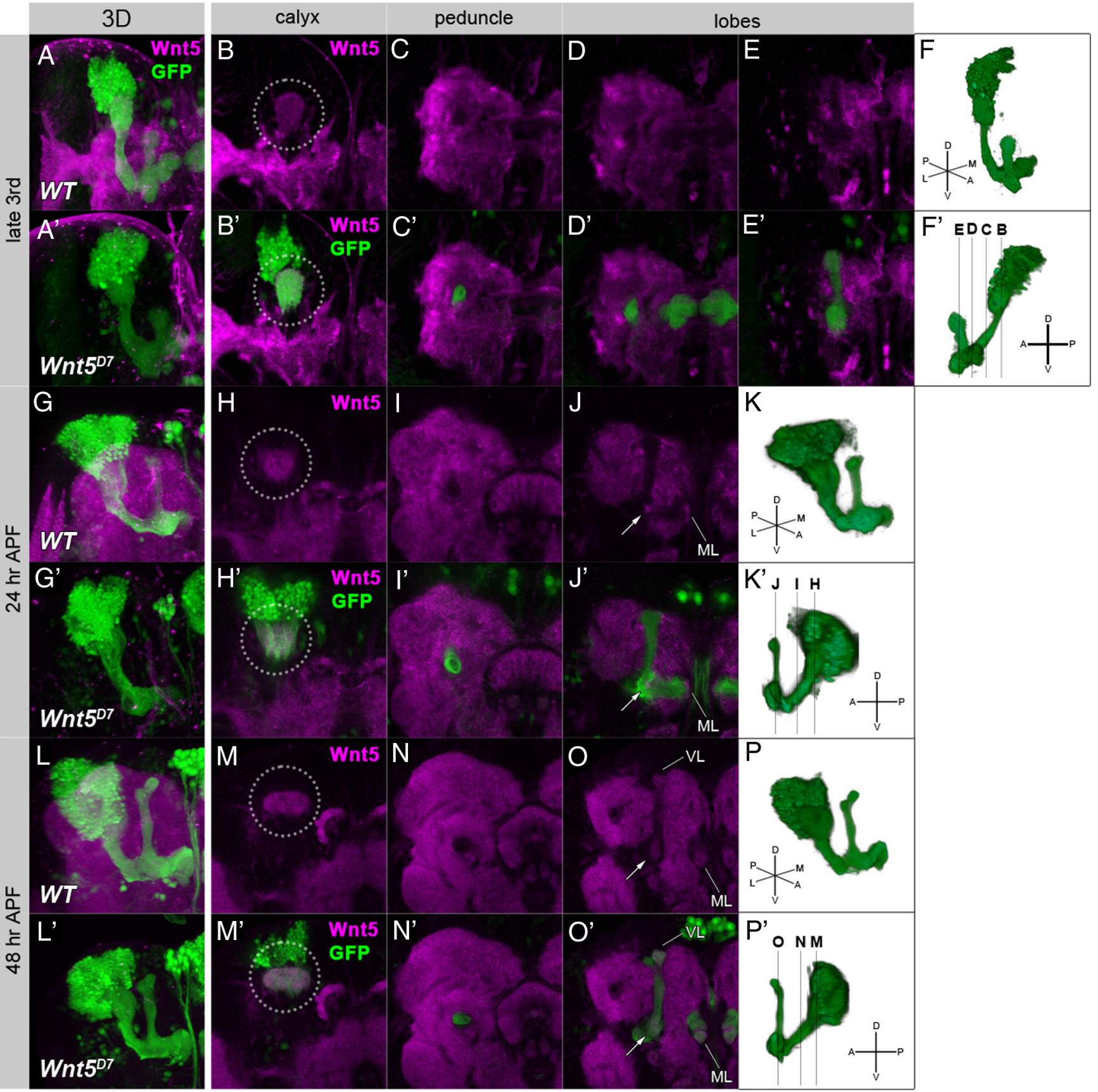

Figure 5. The expression pattern of Wnt5 in the brain. The Wnt5 protein (magenta) was broadly expressed in the brain at the late third larval instar $\left(\boldsymbol{A}, \boldsymbol{B}-\boldsymbol{E}^{\prime}\right), 24 \mathrm{~h} A P F\left(\boldsymbol{G}, \boldsymbol{H}-\boldsymbol{J}^{\prime}\right)$, and $48 \mathrm{~h} \mathrm{APF}\left(\boldsymbol{L}, \boldsymbol{M}-\mathbf{O}^{\prime}\right)$. The signal of Wnt5 was abolished in the brains of Wnt5 mutants at the late third larval instar $\left(\boldsymbol{A}^{\prime}\right), 24 \mathrm{~h}$ APF $\left(\boldsymbol{G}^{\prime}\right)$, and $48 \mathrm{~h}$ APF $\left(\boldsymbol{L}^{\prime}\right)$. Three-dimensional reconstructed images $\left(\boldsymbol{A}, \boldsymbol{A}^{\prime}, \mathbf{G}, \boldsymbol{G}^{\prime}, \boldsymbol{L}, \boldsymbol{L}^{\prime}\right)$ and sections at the level of the calyx $\left(\boldsymbol{B}, \boldsymbol{B}^{\prime}, \boldsymbol{H}, \boldsymbol{H}^{\prime}, \boldsymbol{M}, \boldsymbol{M}^{\prime}\right)$, the peduncle $\left(\boldsymbol{C}, \boldsymbol{C}^{\prime}, \boldsymbol{I}, \boldsymbol{I}^{\prime}, \boldsymbol{N}, \boldsymbol{N}^{\prime}\right)$, and the lobes $\left(\boldsymbol{D}-\boldsymbol{E}^{\prime}, \boldsymbol{J}, \boldsymbol{J}^{\prime}, \mathbf{O}, \boldsymbol{O}^{\prime}\right)$ are indicated. The structure of the MB was visualized by the expression of GFP (green) driven by 0 K107-Gal4. The level of each section is schematically illustrated in lateral views of the MB at each stage $\left(\boldsymbol{F}^{\prime}, \boldsymbol{K}^{\prime}, \boldsymbol{P}^{\prime}\right)$. Wnt5 was localized in the calyx $\left(\boldsymbol{B}, \boldsymbol{B}^{\prime}, \boldsymbol{H}, \boldsymbol{H}^{\prime}, \boldsymbol{M}, \boldsymbol{M}^{\prime}\right.$, dotted circles) at all stages. At $24 \mathrm{~h}$ APF, Wnt5 was also detected at the branch point of the lobes $\left(\boldsymbol{J}, \boldsymbol{J}^{\prime}\right.$, arrow) and at the tip of the medial lobe $\left(\boldsymbol{J}, \boldsymbol{J}^{\prime}, \mathrm{ML}\right)$. At $48 \mathrm{~h} \mathrm{APF}$, Wnt5 was accumulated at the branch point of the lobes $\left(\mathbf{0}, \mathbf{0}^{\prime}\right.$, arrow) and at the tips of both the vertical and the medial lobes $\left(\mathbf{0}, \mathbf{0}^{\prime}, \mathrm{VL}\right.$ and $\left.\mathrm{ML}\right)$.

in the rescue experiments of the PCP mutants. Because it was reported that the $W n t 5$ mutant phenotype was rescued by restoring Wnt5 expression using MB-specific Gal4 lines (Grillenzoni et al., 2007), we confirmed this result with a different mutant allele of $W n t 5\left(W n t 5^{D 7}\right)$ than was used by Grillenzoni et al. $\left(W n t 5^{400}\right)$. Whereas the Wnt5 mutant showed the posterior aggregation, the lobe loss and the lobe reduction phenotype with a penetrance of $3.13,64.4$, and $0.00 \%$, respectively, the MB-specific expression of Wnt5 suppressed these phenotypes to $0.00,5.00$, and $36.0 \%$ using OK107-Gal4, 0.00, 24.0, and 21.0\% using 247-Gal4, and 0.00,
35.7, and $21.4 \%$ using $c 739-$-Gal4 (Fig. $6 A$ ). We next examined the expression pattern of Wnt5 in the rescued flies and verified that Wnt5 was restored in the calyx (Fig. $6 B-P^{\prime \prime}$, dotted circle). However, Wnt5 was restored not only in the whole MB, but also in the surrounding neuropile regions, partially mimicking the Wnt5 expression pattern of the wild-type brains (Fig. 6, compare $\left.B-D^{\prime \prime}, H-P^{\prime \prime}\right)$. This result suggests that the Wnt5 that was expressed in the MB diffused into the whole brain. Next, we induced the Wnt5 MARCM clone in KCs to clarify whether the KCs contribute to the expression of Wnt5 in the calyx. When a neuroblast clone 

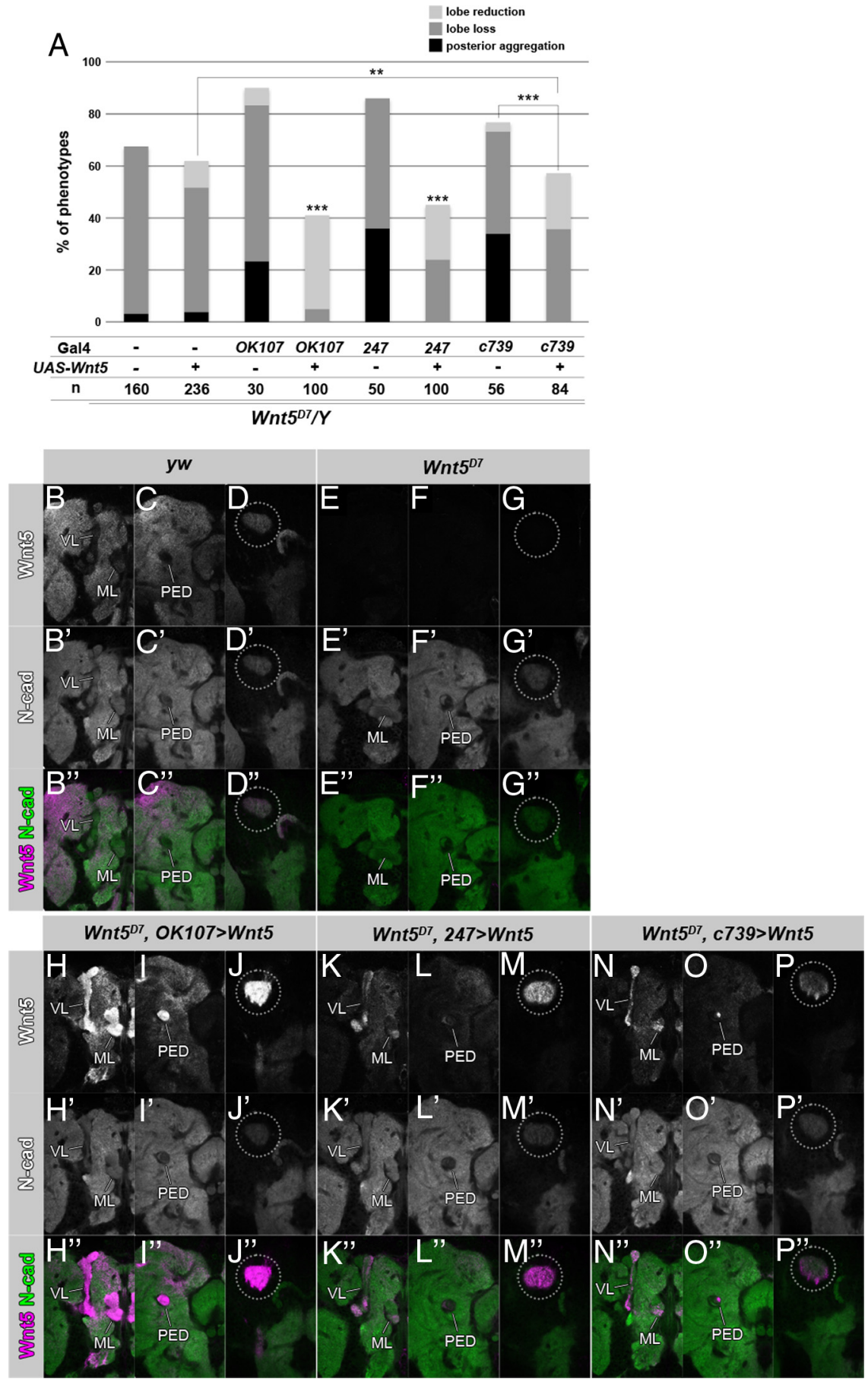

Figure 6. MB specific rescue of the Wnt5 mutants. $A$, Specific restoration of Wnt5 expression in the MB using the indicated Gal4 lines rescued the Wnt5 mutant phenotypes ${ }^{(* *} p<0.001,{ }^{* *} p<0.01$, Fisher's exact test). $\boldsymbol{B}-\boldsymbol{P}^{\prime \prime}$, Wnt5 was restored in the calyx by the expression of Wnt5 in the MBs of the Wnt $5^{D 7}$ mutants. Wnt5 is indicated in white $(\boldsymbol{B}-\boldsymbol{P})$ or magenta $\left(\boldsymbol{B}^{\prime \prime}-\boldsymbol{P}^{\prime}\right)$, and $\mathrm{N}$-cadherin is indicated in white $\left(\boldsymbol{B}^{\prime}-\boldsymbol{P}^{\prime}\right)$ or green $\left(\boldsymbol{B}^{\prime \prime}-\boldsymbol{P}^{\prime}\right)$. OK107-Gal4 $\left(\boldsymbol{H}-\boldsymbol{J}^{\prime}\right)$, 247-Gal4 $\left(\boldsymbol{K}-\boldsymbol{M}^{\prime \prime}\right)$, or $\left(\mathbf{B} 39-\right.$ Gal4 $\left(\boldsymbol{N}-\boldsymbol{P}^{\prime}\right)$ was used. The expression patterns of Wnt5 in $y w\left(\boldsymbol{B}-\boldsymbol{D}^{\prime \prime}\right)$ and $W n t 5^{57}\left(\boldsymbol{E}-\boldsymbol{G}^{\prime \prime}\right)$ are shown as positive and negative staining controls, respectively. Sections of the hemispheres of $48 \mathrm{~h}$ pupal brains at the level of the lobes $\left(\boldsymbol{B}-\boldsymbol{B}^{\prime \prime}, \boldsymbol{E}-\boldsymbol{E}^{\prime}, \boldsymbol{H}-\boldsymbol{H}^{\prime \prime}, \boldsymbol{K}-\boldsymbol{K}^{\prime \prime}, \boldsymbol{N}-\boldsymbol{N}^{\prime \prime}\right)$, the peduncle $\left(\boldsymbol{C}-\boldsymbol{C}^{\prime \prime}, \boldsymbol{F}-\boldsymbol{F}^{\prime}, \boldsymbol{I}-\boldsymbol{I}^{\prime \prime}, \boldsymbol{L}-\boldsymbol{L}^{\prime \prime}, \mathbf{O}-\boldsymbol{O}^{\prime}\right)$, and the calyx $\left(D-D^{\prime}, G-G^{\prime \prime}, J-J^{\prime}, M-M^{\prime \prime}, P-P^{\prime}\right)$ are indicated. Wnt5 was restored in the calyx to a level higher than that of the wild type (compare the encircled areas in $\mathbf{D}, \boldsymbol{D}^{\prime}$, and $\left.\boldsymbol{J}, \boldsymbol{J}^{\prime \prime}, \boldsymbol{M}, \boldsymbol{M}^{\prime \prime}, \boldsymbol{P}, \boldsymbol{P}^{\prime}\right)$. Wnt5 was detected not only in the whole $\mathrm{MB}\left(\boldsymbol{H}, \boldsymbol{H}^{\prime}, \boldsymbol{K}, \boldsymbol{K}^{\prime \prime}, \boldsymbol{N}, \boldsymbol{N}^{\prime}, \mathrm{VL}, \mathrm{ML} ; \boldsymbol{I}, \boldsymbol{I}^{\prime}, \boldsymbol{L}, \mathbf{L}^{\prime \prime}, \mathbf{O}, \mathbf{O}^{\prime \prime}\right.$, PED) but also in the surrounding neuropile regions $\left(H, H^{\prime}, I, I^{\prime \prime}, K, K^{\prime \prime}, L, L^{\prime \prime}, N, N^{\prime \prime}, \mathbf{O}, \mathbf{O}^{\prime \prime}\right)$.

was induced in the KCs, the Wnt5 protein was slightly decreased in the mutant clone (Fig. $7 A-A^{\prime \prime}$ ), whereas the expression level of $\mathrm{N}$-cadherin was not changed (Fig. $7 B-B^{\prime \prime}$ ). Because the density of the dendrites in the calyx is not uniform, we calibrated the signal intensity of Wnt5 by normalizing to the signal intensity of $\mathrm{N}$-cadherin.
Wnt 5 was clearly decreased in the Wnt5 mutant clone (Fig. 7C). This result suggests that the Wnt5 that was expressed in the KCs contributed to its accumulation in the calyx. In support of this notion, administration of MB-specific RNAi against Wnt5 resulted in decreased levels of Wnt5 in the calyx (data not shown). However, the possibility that cells other than the KCs contribute to the accumulation of Wnt5 in the calyx cannot be excluded because Wnt5 was not abolished completely in a Wnt5 mutant clone.

\section{Discussion}

The functions of the PCP signal in polarity formation within a plane of epithelium and convergent extension have been extensively studied for many years (Axelrod et al., 1998; Simons and Mlodzik, 2008; Roszko et al., 2009). Recently, PCP genes have been revealed to be involved in neural development, including asymmetric cell division (Gho and Schweisguth, 1998; Lake and Sokol, 2009), neural migration (Wada and Okamoto, 2009), axonal extension/retraction (Kishida et al., 2004; Okuda et al., 2007; Shima et al., 2007; Fujimura et al., 2009), axon guidance (Wang et al., 2002, 2006; Lyuksyutova et al., 2003; Tissir et al., 2005; Zhou et al., 2008), target recognition (Lee et al., 2003; Senti et al., 2003; Chen and Clandinin, 2008), and dendritic growth and maintenance (Shima et al., 2004, 2007). However, the functional relationships among the PCP components remain elusive, and it is unclear whether the same PCP signaling pathway used in planar polarization is also used in neural development. Moreover, Wnt as a ligand for the PCP pathway has not been identified in Drosophila (Simons and Mlodzik, 2008; Axelrod, 2009). In this study, we demonstrated that the PCP genes regulated axonal morphogenesis of the $\mathrm{MB}$ and genetically interacted during this process. Moreover, we found that Wnt5, which has been previously reported to be required for the development of the MB (Grillenzoni et al., 2007), genetically interacted with the PCP components. These findings emphasize the importance of Wnt5 and its downstream PCP signal in the axonal development of the MB.

\section{Novel roles of the PCP signal in axonal development}

Several recent studies have reported that some of the PCP genes are required for axon tract formation in mice. Mutants of Fz3 and Celsr3, a mammalian homolog of Drosophila fmi, display similar defects in axonal tract formation (Wang et al., 2002, 2006; Tissir et al., 2005; Zhou et al., 2008), and 


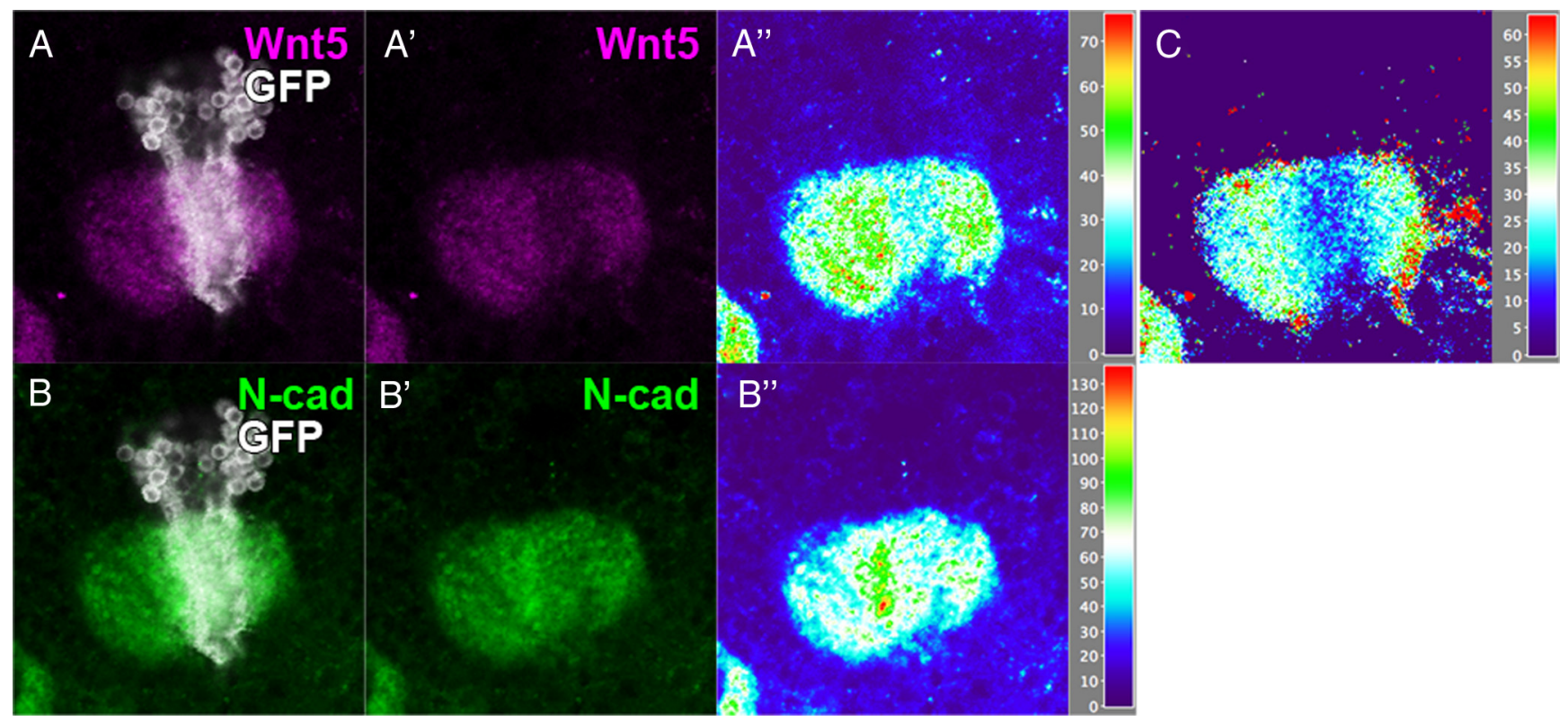

Figure 7. Wnt5 is expressed in the KCs. Expression of Wnt5 $\left(\boldsymbol{A}, \boldsymbol{A}^{\prime}\right.$, magenta) is slightly reduced in a clone of the $W n t 5$ mutant $(\boldsymbol{A}, \boldsymbol{B}$, white) induced in the $\mathrm{MB}$, but the signal intensity of $\mathrm{N}$-cadherin $\left(\boldsymbol{B}, \boldsymbol{B}^{\prime}\right.$, green) is not changed within the clone. The signal intensities of Wnt5 $\left(\boldsymbol{A}^{\prime \prime}\right)$ and $\mathrm{N}$-cadherin $\left(\boldsymbol{B}^{\prime \prime}\right)$ were visualized by the height of the peaks in 2.5 -dimensional images. $\boldsymbol{C}$, The signal intensity of Wnt 5 was calibrated using the signal intensity of $\mathrm{N}$-cadherin to eliminate the influence from potential differences in dendritic densities. Wnt 5 was clearly decreased in the Wnt5 mutant clone.

other PCP genes are expressed in a similar pattern in the mouse brain (Tissir and Goffinet, 2006). In addition, Wnt/PCP signaling components were reported to control the anteroposterior organization of the brainstem (Fenstermaker et al., 2010). Drosophila Fmi and mammalian Celsr2 and Celsr3 regulate neurite outgrowth independent of the PCP pathway (Gao et al., 2000; Shima et al., 2004, 2007). However, it is not known whether these genes genetically interact in axonal tract formation or whether they use an intracellular signaling pathway analogous to the PCP signal. Here, we showed that disruptions of several PCP genes displayed similar phenotypes in the axonal development of the $\mathrm{MB}$ and showed a genetic interaction (Fig. 2). The fact that $d s h^{1}$, a hypomorphic allele of $d s h$, showed genetic interaction with other PCP genes supports the notion that this process uses intracellular signaling similar to the PCP signal because $d s h^{1}$ is a mutation that mainly affects the PCP pathway in Drosophila (Axelrod et al., 1998; Boutros et al., 1998). The observed tendency that the vertical lobes were more affected than the medial lobes in the $f z^{H 51} / f z^{D 21}$ and $d s h^{1}$ mutants and the medial lobes were more affected than the vertical lobes in the $s t b m^{s t b m-6} / \mathrm{stbm}^{A 3}$ mutants may somewhat reflect the asymmetric functions of Fz, Dsh, and Stbm.

\section{Interaction between Wnt5 and PCP components}

A Wnt ligand had not yet been identified in the Drosophila PCP signaling pathway. Here, we identified Wnt5 as a ligand for the PCP pathway. We showed that mutants of $W n t 5$ and the PCP genes displayed similar phenotypes at the single-cell level (Figs. 2, 4) and genetically interacted in various combinations (Fig. 4). However, there were some differences in the penetrance of each phenotype between the Wnt5 mutant and the mutants of the PCP genes; for example, 83.3, 55.0, 37.5, and $64.4 \%$ of cases showed the lobe loss phenotype in $f z^{H 51} / \mathrm{fz}^{D 21}, s t b m^{\text {stbm-6}} / s t b m^{A 3}, d s h^{1}$, and $W n t 5^{D 7}$ mutants, respectively. These results may indicate that there is some function of Wnt5 that is independent of the PCP components and vice versa.
A mechanism by which targeting defects of individual axons led to the absence of whole lobes

Whereas we observed the loss of whole lobes in the PCP and Wnt5 mutants, individual axons in these mutants showed targeting and branching defects. Why do targeting defects of individual axons lead to the loss of whole lobes? Because the developing axons are projected into the core of the peduncles and lobes, we speculate that newly extending axons would follow the path that was already established by previously projected axons. If the axons of young $\alpha / \beta$ neurons, which play a pioneering role, adopt the correct path by chance, an intact lobe structure will form regardless of the phenotypes of the following axons. However, if the majority of young axons choose the wrong path, a defective lobe structure will form. We speculate that the overall $\alpha / \beta$ lobe phenotype is mostly dependent on the projection of young $\alpha / \beta$ neurons.

\section{Molecular function of Wnt5 in the axon targeting and branching of the MB}

In the last decade, Wnts, including Drosophila Wnt5, have been implicated as conserved axon guidance molecules (Lyuksyutova et al., 2003; Yoshikawa et al., 2003; Liu et al., 2005; Sato et al., 2006; Schmitt et al., 2006). In these examples, Wnts were localized to a specific region and had instructive roles. However, it is unlikely that Wnt5 functions as an axon guidance cue in the development of the MB because Wnt5 was broadly expressed in the developing brain. Wnts are also assumed to function as permissive cues upstream of the core PCP components in convergent extension in zebrafish because the uniform injection of $w n t 11 / s l b$ or $w n t 5 / p p t$ mRNA rescued the Wnt11/slb mutant, although the distribution of Wnt11/Slb or Wnt5/Ppt proteins was not examined (Heisenberg et al., 2000; Kilian et al., 2003). We speculate that Wnt5 plays a similar role to zebrafish Wnt5b or Wnt11 because Wnt5 protein was expressed in the calyx, but not in the core of the lobes, in which the newly extending axons pass through. In this scenario, the PCP signaling pathway is potentiated in the growth cones of the KCs on the reception of Wnt5. 
Wnt5 is expressed from the dendrites of the older KCs and regulates the axonal development of the younger KCs. During the initial phase of projection, the growth cones of the KCs receive Wnt5 when they pass through the calyx, and the PCP pathway, potentiated by the $\mathrm{Wnt5}$, regulates axonal projection and branching. This may be the underlying cause of the aggregation of axons beside the calyx and the loss of the lobes.

\section{Possible functions of the PCP signal in axonal targeting and branching of KCs}

Based on the analysis of the PCP genes at the single-cell level, these genes are required for axonal targeting and branching. During pathfinding, the growth cones at the tips of primary axons must detect small differences in the concentration gradients of attractive and repulsive cues because the width of the $\mathrm{KC}$ growth cone is very small $(<1 \mu \mathrm{m})$ (data not shown). Axonal branching can also be considered a polarized cellular process, and thus it encounters problems that are similar to that found in the axonal guiding process. To overcome this difficulty, signals from the external environment need to be amplified within the growth cone. The most prominent molecular feature of the PCP components, the ability to generate polarity within a cell that is generated by reciprocal negative feedback between the Stbm and Fz complexes, may regulate this amplification process. In this model, ligand binding to its receptor activates the PCP signal. PCP components change their distribution from a symmetric to an asymmetric manner within a growth cone and form a receptor complex with the guidance receptor, which leads to the asymmetric distribution of the guidance receptor with a higher concentration at the side closer to the source of the guidance cue, for example. A small difference in the concentration of a guidance cue in the external environment is converted to a large difference in signal strength within a growth cone via the PCP machinery, although we could not detect any alteration in the distribution of $\mathrm{Fz}$, Stbm, or Fmi in Wnt5 mutants at the immunohistochemical level. One candidate molecule that links axon guidance receptors and the PCP components is PTK7, which forms a complex with Plexin-A1, genetically interacts with Vangl2, and recruits Dsh to the plasma membrane (Lu et al., 2004; Toyofuku et al., 2004; Shnitsar and Borchers, 2008). Although off-track (otk), the Drosophila homolog of PTK7, is not reported to function in the PCP formation, OTK associates with Plexin-A to form a receptor complex downstream of Semaphorin 1a during axon guidance (Winberg et al., 2001). In addition, RNAi knockdown of otk showed a loss or reduction of the $\alpha / \beta$ lobes (our unpublished observations).

Additional study is needed to reveal the relationship between Wnt5 and the PCP signaling pathway in axonal development and the molecular entity that links axon guidance and the PCP signal.

\section{References}

Axelrod JD (2001) Unipolar membrane association of Dishevelled mediates Frizzled planar cell polarity signaling. Genes Dev 15:1182-1187.

Axelrod JD (2009) Progress and challenges in understanding planar cell polarity signaling. Semin Cell Dev Biol 20:964-971.

Axelrod JD, Miller JR, Shulman JM, Moon RT, Perrimon N (1998) Differential recruitment of Dishevelled provides signaling specificity in the planar cell polarity and Wingless signaling pathways. Genes Dev 12:2610-2622.

Bastock R, Strutt D (2007) The planar polarity pathway promotes coordinated cell migration during Drosophila oogenesis. Development 134:3055-3064.

Bastock R, Strutt H, Strutt D (2003) Strabismus is asymmetrically localised and binds to Prickle and Dishevelled during Drosophila planar polarity patterning. Development 130:3007-3014.
Boutros M, Paricio N, Strutt DI, Mlodzik M (1998) Dishevelled activates JNK and discriminates between JNK pathways in planar polarity and wingless signaling. Cell 94:109-118.

Chen PL, Clandinin TR (2008) The cadherin Flamingo mediates leveldependent interactions that guide photoreceptor target choice in Drosophila. Neuron 58:26-33.

Chilton JK (2006) Molecular mechanisms of axon guidance. Dev Biol 292:13-24.

Connolly JB, Roberts IJ, Armstrong JD, Kaiser K, Forte M, Tully T, O’Kane CJ (1996) Associative learning disrupted by impaired G(s) signaling in Drosophila mushroom bodies. Science 274:2104-2107.

Crittenden JR, Skoulakis EM, Han KA, Kalderon D, Davis RL (1998) Tripartite mushroom body architecture revealed by antigenic markers. Learn Mem 5:38-51.

Feiguin F, Hannus M, Mlodzik M, Eaton S (2001) The ankyrin repeat protein Diego mediates Frizzled-dependent planar polarization. Dev Cell 1:93-101.

Fenstermaker AG, Prasad AA, Bechara A, Adolfs Y, Tissir F, Goffinet A, Zou Y, Pasterkamp RJ (2010) Wnt/planar cell polarity signaling controls the anterior-posterior organization of monoaminergic axons in the brainstem. J Neurosci 30:16053-16064.

Fradkin LG, Noordermeer JN, Nusse R (1995) The Drosophila Wnt protein DWnt-3 is a secreted glycoprotein localized on the axon tracts of the embryonic CNS. Dev Biol 168:202-213.

Fradkin LG, van Schie M, Wouda RR, de Jong A, Kamphorst JT, RadjkoemarBansraj M, Noordermeer JN (2004) The Drosophila Wnt5 protein mediates selective axon fasciculation in the embryonic central nervous system. Dev Biol 272:362-375.

Fujimura L, Watanabe-Takano H, Sato Y, Tokuhisa T, Hatano M (2009) Prickle promotes neurite outgrowth via the Dishevelled dependent pathway in C1300 cells. Neurosci Lett 467:6-10.

Gao FB, Kohwi M, Brenman JE, Jan LY, Jan YN (2000) Control of dendritic field formation in Drosophila: the roles of flamingo and competition between homologous neurons. Neuron 28:91-101.

Gho M, Schweisguth F (1998) Frizzled signalling controls orientation of asymmetric sense organ precursor cell divisions in Drosophila. Nature 393:178-181.

Grillenzoni N, Flandre A, Lasbleiz C, Dura JM (2007) Respective roles of the DRL receptor and its ligand WNT5 in Drosophila mushroom body development. Development 134:3089-3097.

Gros J, Serralbo O, Marcelle C (2009) WNT11 acts as a directional cue to organize the elongation of early muscle fibres. Nature 457:589-593.

Gubb D, Green C, Huen D, Coulson D, Johnson G, Tree D, Collier S, Roote J (1999) The balance between isoforms of the prickle LIM domain protein is critical for planar polarity in Drosophila imaginal discs. Genes Dev 13:2315-2327.

Heisenberg CP, Tada M, Rauch GJ, Saúde L, Concha ML, Geisler R, Stemple DL, Smith JC, Wilson SW (2000) Silberblick/Wnt11 mediates convergent extension movements during zebrafish gastrulation. Nature 405:76-81.

Huang Z, Kunes S (1996) Hedgehog, transmitted along retinal axons, triggers neurogenesis in the developing visual centers of the Drosophila brain. Cell 86:411-422.

Jones KH, Liu J, Adler PN (1996) Molecular analysis of EMS-induced frizzled mutations in Drosophila melanogaster. Genetics 142:205-215.

Kilian B, Mansukoski H, Barbosa FC, Ulrich F, Tada M, Heisenberg CP (2003) The role of Ppt/Wnt5 in regulating cell shape and movement during zebrafish gastrulation. Mech Dev 120:467-476.

Kishida S, Yamamoto H, Kikuchi A (2004) Wnt-3a and Dvl induce neurite retraction by activating Rho-associated kinase. Mol Cell Biol 24:4487-4501.

Komiyama T, Sweeney LB, Schuldiner O, Garcia KC, Luo L (2007) Graded expression of semaphorin-1a cell-autonomously directs dendritic targeting of olfactory projection neurons. Cell 128:399-410.

Lake BB, Sokol SY (2009) Strabismus regulates asymmetric cell divisions and cell fate determination in the mouse brain. J Cell Biol 185:59-66.

Lee RC, Clandinin TR, Lee CH, Chen PL, Meinertzhagen IA, Zipursky SL (2003) The protocadherin Flamingo is required for axon target selection in the Drosophila visual system. Nat Neurosci 6:557-563.

Lee T, Luo L (1999) Mosaic analysis with a repressible cell marker for studies of gene function in neuronal morphogenesis. Neuron 22:451-461.

Lee T, Lee A, Luo L (1999) Development of the Drosophila mushroom bod- 
ies: sequential generation of three distinct types of neurons from a neuroblast. Development 126:4065-4076.

Liu Y, Shi J, Lu CC, Wang ZB, Lyuksyutova AI, Song X, Zou Y (2005) Rykmediated Wnt repulsion regulates posterior-directed growth of corticospinal tract. Nat Neurosci 8:1151-1159.

Lu X, Borchers AG, Jolicoeur C, Rayburn H, Baker JC, Tessier-Lavigne M (2004) PTK7/CCK-4 is a novel regulator of planar cell polarity in vertebrates. Nature 430:93-98.

Lyuksyutova AI, Lu CC, Milanesio N, King LA, Guo N, Wang Y, Nathans J, Tessier-Lavigne M, Zou Y (2003) Anterior-posterior guidance of commissural axons by Wnt-frizzled signaling. Science 302:1984-1988.

Okuda H, Miyata S, Mori Y, Tohyama M (2007) Mouse Pricklel and Prickle2 are expressed in postmitotic neurons and promote neurite outgrowth. FEBS Lett 581:4754-4760.

Rawls AS, Wolff T (2003) Strabismus requires Flamingo and Prickle function to regulate tissue polarity in the Drosophila eye. Development 130:1877-1887.

Roszko I, Sawada A, Solnica-Krezel L (2009) Regulation of convergence and extension movements during vertebrate gastrulation by the Wnt/PCP pathway. Semin Cell Dev Biol 20:986-997.

Rulifson EJ, Micchelli CA, Axelrod JD, Perrimon N, Blair SS (1996) wingless refines its own expression domain on the Drosophila wing margin. Nature 384:72-74.

Sato M, Umetsu D, Murakami S, Yasugi T, Tabata T (2006) DWnt4 regulates the dorsoventral specificity of retinal projections in the Drosophila melanogaster visual system. Nat Neurosci 9:67-75.

Schmitt AM, Shi J, Wolf AM, Lu CC, King LA, Zou Y (2006) Wnt-Ryk signalling mediates medial-lateral retinotectal topographic mapping. Nature 439:31-37.

Senti KA, Usui T, Boucke K, Greber U, Uemura T, Dickson BJ (2003) Flamingo regulates $\mathrm{R} 8$ axon-axon and axon-target interactions in the Drosophila visual system. Curr Biol 13:828-832.

Shima Y, Kengaku M, Hirano T, Takeichi M, Uemura T (2004) Regulation of dendritic maintenance and growth by a mammalian 7-pass transmembrane cadherin. Dev Cell 7:205-216.

Shima Y, Kawaguchi SY, Kosaka K, Nakayama M, Hoshino M, Nabeshima Y, Hirano T, Uemura T (2007) Opposing roles in neurite growth control by two seven-pass transmembrane cadherins. Nat Neurosci 10:963-969.

Shnitsar I, Borchers A (2008) PTK7 recruits dsh to regulate neural crest migration. Development 135:4015-4024.

Simons M, Mlodzik M (2008) Planar cell polarity signaling: from fly development to human disease. Annu Rev Genet 42:517-540.

Takei Y, Ozawa Y, Sato M, Watanabe A, Tabata T (2004) Three Drosophila EXT genes shape morphogen gradients through synthesis of heparan sulfate proteoglycans. Development 131:73-82.
Takeichi M (2007) The cadherin superfamily in neuronal connections and interactions. Nat Rev Neurosci 8:11-20.

Taylor J, Abramova N, Charlton J, Adler PN (1998) Van Gogh: a new Drosophila tissue polarity gene. Genetics 150:199-210.

Tissir F, Goffinet AM (2006) Expression of planar cell polarity genes during development of the mouse CNS. Eur J Neurosci 23:597-607.

Tissir F, Goffinet AM (2010) Planar cell polarity signaling in neural development. Curr Opin Neurobiol 20:572-577.

Tissir F, Bar I, Jossin Y, De Backer O, Goffinet AM (2005) Protocadherin Celsr3 is crucial in axonal tract development. Nat Neurosci 8:451-457.

Toyofuku T, Zhang H, Kumanogoh A, Takegahara N, Suto F, Kamei J, Aoki K, Yabuki M, Hori M, Fujisawa H, Kikutani H (2004) Dual roles of Sema6D in cardiac morphogenesis through region-specific association of its receptor, Plexin-A1, with off-track and vascular endothelial growth factor receptor type 2. Genes Dev 18:435-447.

Usui T, Shima Y, Shimada Y, Hirano S, Burgess RW, Schwarz TL, Takeichi M, Uemura T (1999) Flamingo, a seven-pass transmembrane cadherin, regulates planar cell polarity under the control of Frizzled. Cell 98:585-595.

Wada H, Okamoto H (2009) Roles of planar cell polarity pathway genes for neural migration and differentiation. Dev Growth Differ 51:233-240.

Wang Y, Thekdi N, Smallwood PM, Macke JP, Nathans J (2002) Frizzled-3 is required for the development of major fiber tracts in the rostral CNS. J Neurosci 22:8563-8573.

Wang Y, Zhang J, Mori S, Nathans J (2006) Axonal growth and guidance defects in Frizzled3 knock-out mice: a comparison of diffusion tensor magnetic resonance imaging, neurofilament staining, and genetically directed cell labeling. J Neurosci 26:355-364.

Winberg ML, Tamagnone L, Bai J, Comoglio PM, Montell D, Goodman CS (2001) The transmembrane protein Off-track associates with Plexins and functions downstream of Semaphorin signaling during axon guidance. Neuron 32:53-62.

Wolff, Rubin GM (1998) Strabismus, a novel gene that regulates tissue polarity and cell fate decisions in Drosophila. Development 125:1149-1159.

Yao Y, Wu Y, Yin C, Ozawa R, Aigaki T, Wouda RR, Noordermeer JN, Fradkin LG, Hing H (2007) Antagonistic roles of Wnt5 and the Drl receptor in patterning the Drosophila antennal lobe. Nat Neurosci 10:1423-1432.

Yoshikawa S, McKinnon RD, Kokel M, Thomas JB (2003) Wnt-mediated axon guidance via the Drosophila Derailed receptor. Nature 422:583-588.

Zhou L, Bar I, Achouri Y, Campbell K, De Backer O, Hebert JM, Jones K, Kessaris N, de Rouvroit CL, O'Leary D, Richardson WD, Goffinet AM, Tissir F (2008) Early forebrain wiring: genetic dissection using conditional Celsr3 mutant mice. Science 320:946-949. 